\title{
Hyperthermia exaggerates exercise-induced aggregation of blood platelets
}

\author{
Jung-Hyun Kim, Tianzhou Wu, Raymond Roberge, Aitor Coca \\ From 15th International Conference on Environmental Ergonomics (ICEE XV) \\ Portsmouth, UK. 28 June - 3 July 2015
}

\begin{abstract}
Introduction
Acute exposure to exertional exercise/heavy physical work often triggers cardiovascular events in which exerciseinduced platelet aggregation, blood coagulation, and disruption in fibrinolysis may adversely affect atherothrombotic disease. Elevated body temperature, commonly accompanied with prolonged exercise, was suggested as an auxiliary factor for exercise-induced platelet aggregation [1]. Recent studies also showed platelet hyperaggregation following firefighting activities combining heavy physical work and heat stress [2], [3]. However, the influence of hyperthermia separated from physical exercise impact on platelet aggregation is unclear.
\end{abstract}

\section{Methods}

Twelve healthy men; age 22.8 (1.3) years and $\mathrm{VO}_{2 \max }$ 56.8 (6.2) $\mathrm{ml} \cdot \mathrm{kg}^{-1} \cdot \mathrm{min}^{-1}$, underwent three experimental trials: exercise hyperthermia (ExHT), passive hyperthermia $(\mathrm{PaHT})$, and control exercise (CONT). Subjects performed a treadmill exercise at $60 \% \mathrm{VO}_{2 \max }$ in the heat $\left(35{ }^{\circ} \mathrm{C}, 50 \% \mathrm{RH}\right)$ until their rectal temperature $\left(\mathrm{T}_{\text {re }}\right)$ increased $1.5{ }^{\circ} \mathrm{C}$ above the resting baseline (ExHT) or performed a control exercise at the same intensity and duration according to ExHT in a cooler condition $\left(23^{\circ} \mathrm{C}\right.$, $50 \% \mathrm{RH})$ (CONT). In PaHT, subjects were passively heated using a water garment $\left(45^{\circ} \mathrm{C}\right)$ in the heat $\left(45^{\circ} \mathrm{C}\right.$, $50 \% \mathrm{RH})$ until $\mathrm{T}_{\mathrm{re}}$ increased $1.5^{\circ} \mathrm{C}$ above baseline. Platelet aggregation was assessed from antecubital venous blood collected during baseline (Base), end-trial (End), and again following 1 hour of passive recovery $(\operatorname{Rec})\left(23{ }^{\circ} \mathrm{C}, 50 \%\right.$ $\mathrm{RH})$, using a platelet function analyser providing a closure time (CT: second) through an in-vitro simulation of platelet adhesion, activation, and aggregation. Decreased CT is

\footnotetext{
* Correspondence: inr3@cdc.gov

National Personal Protective Technology Laboratory, National Institute for Occupational Safety and Health, Centers for Disease Control and Prevention, Pittsburgh, PA, USA
}

\section{Results}

Under the study conditions, $\mathrm{T}_{\text {re }}(F=13.2, p<0.001)$ and in temperature $(F=97.3, p<0.001)$ increased significontly in ExHT and PaHT compared to CONT, whereas ate was significantly higher in ExHT and CONT Cored to PaHT $(F=40.0, p<0.001)$. CT in exposure Collagen/ADP showed a decreasing trend over time in (and significantly differed from CONT Expec $(F=7.6, p=0.008)$. CT in exposure to Collagen/ binephrine showed a similar response to Collagen/ADP, $p=0.075)$ though $C \mathrm{~T}$ in ExHT significantly decred End compared to CT in CONT $(p=0.046)$.

\section{Discussion}

Moderate exercise in the heat (ExHT) significantly elevated platelet aggregation as indicated by decreased CT whereas $\mathrm{CT}$ was not altered in non-hyperthermia exercise condition (CONT). PaHT showed an overall decreasing trend of CT toward End and Rec, but its impact on platelet aggregation was not significant in response to C/EPI in this study.

\section{Conclusion}

It was concluded that hyperthermia exaggerates exercise-induced platelet aggregation as an auxiliary factor, but the effect of hyperthermia alone on platelet aggregation in young, healthy subjects is minimal. Further research is warranted to investigate a physiological mechanism responsible for hyperthermia induced-platelet hyperreactivity. 


\section{Disclaimer}

The findings and conclusions of this abstract are those of the authors and do not necessarily reflect the views of the National Institute for Occupational Safety and Health.

Published: 14 September 2015

\section{References}

1. El-Sayed MS, Ali N, El-Sayed Ali Z: Aggregation and activation of blood platelets in exercise and training. Sports Med 2005, 35(1):11-22.

2. Smith $\mathrm{DL}$, et al: Effect of live-fire training drills on firefighters' platelet number and function. Prehosp Emerg Care 2011, 15(2):233-9.

3. Hostler $D$, et al: A randomized controlled trial of aspirin and exertional heat stress activation of platelets in firefighters during exertion in thermal protective clothing. Prehosp Emerg Care 2014, 18(3):359-67.

doi:10.1186/2046-7648-4-S1-A153

Cite this article as: Kim et al:: Hyperthermia exaggerates exerciseinduced aggregation of blood platelets. Extreme Physiology \& Medicine 2015 4(Suppl 1):A153.

Submit your next manuscript to BioMed Central and take full advantage of:

- Convenient online submission

- Thorough peer review

- No space constraints or color figure charges

- Immediate publication on acceptance

- Inclusion in PubMed, CAS, Scopus and Google Scholar

- Research which is freely available for redistribution

Submit your manuscript at www.biomedcentral.com/submit 